\title{
The Effect Of Nursing Application Of Neuromuscular Electrical Stimulation on Mechanically Ventilated Patient's Outcome
}

\author{
Om Elhanaa Ewais Mohamed ${ }^{1}$, Abd-Elrady Shehata ${ }^{2}$, Moggeda Mohamed ${ }^{3}$, GhadaShalaby Khalaf \\ Mahran 4 . \\ 1- Nursing supervisor in Pediatric I.C.U. Assuit University \\ 2- Assist Professor of anesthesia and intensive care, Faculty of Medicine Assuit University. \\ 3- Assist Professorof Critical Care and emergency Nursing Department, Faculty of Nursing Assuit University \\ 4- Lecturer in Critical Care and emergencyNursing Department, Faculty of Nursing Assuit University.
}

\begin{abstract}
Introduction: Intensive care unit acquired muscle weakness is acommon complication of immobility. It is an acquired neuromuscular disorder associated with increased duration of mechanical ventilation and weaning suggesting a possible relation between the limb and respiratory neuromuscular involvement. Aim of study: was to evaluate the effect of nursing application of neuromuscular electrical stimulation on mechanically ventilated patient's outcome. Design: Quasi - experimental research design. Setting: The study was conducted in general intensive care unit and trauma unit at Assuit University Subject: Three tools designed and used by the researcher for collecting data for the study. Tool I: Patient assessment tool that consist of four parts. Too III: Riker sedationagitation scale. Tool III: muscle assessment tool that consist of three parts. Method: the researcher assessed ICUAMW, muscle strength and mortality rate. Results: There was a significant increase in muscle strength interventional group than control group $(47.66 \pm 16.84)$ versus $(23.70 \pm 11.58)$, p. value $>0$, 05 and consequently significant decreases in the incidence of ICU acquired muscle weakness $(24.2 \%)$ versus $(75.8 \%)$. Conclusion: Application of neuromuscular electrical stimulation nursing application had apposite veeffect on MVPatients out comes. Recommendation: Keep the electrical muscle stimulation device available in all the intensive care units.
\end{abstract}

Keywords: Acquired Muscle weakness, Patients Out Comes, Electrical Stimulation, Immobility \& Nursing Application.

\section{Introduction}

The Intensive Care Unit Acquired Muscle Weakness (ICUAMW) is an acquired neuromuscular disorder, which is considered a common complication of critical illness survivors presenting with profound muscle weakness and diminished, or absent deep tendon reflexes which are associated also with increased duration of mechanical ventilation and weaning period suggesting a possible relation between the limb and respiratory neuromuscular involvement. In addition, the syndrome is associated with prolonged hospitalization and increased mortality. The diagnosis requires a reliable bedside muscle strength examination and depends on patient's cooperation and maximal effort. (Ali, et al., 2008)

The major risk factors of ICUAW include inflammation, hyperglycemia, and long duration of immobility, poor nutritional support, mechanical ventilation, neuromuscular blockade, and sepsis. Neuropathy and loss of muscle mass are considered the causes of ICUAW. ICUAW is known to be associated with poor short- and long-term outcomes in critically ill patients. It is related with delayed mechanical ventilation weaning (Woo1K, et al., 2018)

Unfortunately, not all critically ill patients can participate actively in early rehabilitation, often because of the use of sedatives or cognitive impairment (Zanni, et al., 2010) Therefore, in recent years, alternatives have been sought to help critical patients become more active, using passive mobilization strategies that include the neuromuscular electrical stimulation (NMES), an option that has been recently use $\mathrm{d}$ for this purpose (Kho, et al., 2015)

The neuromuscular electrical stimulation is an alternative to mobilize and exercise because it does not require active patient participation and can be used on bedridden patients. Deep muscle electrical stimulation has been shown to be beneficial for patients with muscle weakness developed in the ICU (Poulsen, et al., 2011), with higher (Medical Research Council scores) MRCs in the electrical stimulation groups. Most studies have shown that an electrical stimulation of deep muscle has beneficial effects (Routsi, et al., 2010).

For this reason, the aim of this study was to assess the effect of nursing application of neuromuscular Electrical stimulation on muscle function in critically ill patientsout comes.

\section{Significance of the study}

More than $25 \%$ of ICU patients undergoing mechanical ventilation for 7 or more days have 
clinical evidence of weakness on awakening .Marked diaphragmatic atrophy can be seen $18 \mathrm{~h}$ after the onset of mechanical ventilation, and the onset of weakness may occur as early as ICU day (Lipchitz, 2013)

At Assuit university hospital (2015-2016).The frequency of patients admitted with disease affecting muscle function and causes immobility in the patients is varied according to the disease. Galilean Barrie syndrome represents 10 per months and 100 cases per years. patients connected with MV represent arrange between 10-12 case per months and nearly 90 case per years and muscle weakness represent $60-80 \%$ of immobile patients even this patients connected with MV or not due to their pathological disease.

\section{Aim of the study}

Evaluate the effect of nursing application of neuromuscular electrical stimulation on mechanically ventilated patient's outcome.

\section{Patients \& Method}

Research Design:Quasi -experimental research design was adopted to conduct this study.

Setting: the study was conducted in general intensive care unit and trauma unit at Assuit University from 1/10/2017 -30/4 /2018.

Sampling: purposive sample consisted of 66 adult patients (male and female) in the previous settings were not randomly included in the study; their number was divided equally into two groups (33 control and 33 interventional)

By calculating comparison between proportion of study and control groups (Intensive care unit acquired muscle weakness) according to pilot study; the observed that proportion in control group was 40.6, proportion in study group was 5.1. According to the significance level of 0.05 and a power of 0.8 , it was calculated that the sample size of 30 cases in each group.

\section{Critera Of The Sample \\ Inclusion criteria}

All patients admitted in ICU and attached with mechanical ventilation that their Age $>18$ years old, mechanical ventilation $>2$ days, ICU stay more than 7 days

\section{Exclusion criteria}

Pregnancy, obesity, bone fracture or skin lesions (e.g., burns), pacemaker or implanted cardiac defibrillator, end-stage malignancyanddiseases with systemic vascular involvement such as lupus erythematosus. technical restrictions that did not allow the implementation of EMSsuch as bone fractures or skin lesions.

\section{Hypothesis}

1. There would be a significant improvement in muscle function and strength in the interventional group than control group.

2. There would be a significant improvement in the outcomes of critically ill patients in the interventional group than control group

\section{Research questions}

What is the effect of nursing application of neuromuscular electrical stimulation on mechanically ventilated patient's outcome?

Instrumentation and tools: Three tools designed and used by the researcher for collecting data for the study.

TOOL I: Patient assessment tool.

This tool was developed by the researchers after review of literatures to assess the patient condition to form base line data to be compared with this tool compromised four parts(Karatzanos, et al., 2012).

Part I:Socio-demographic patient's profile that included the patient's names, age, sex,

Part II: patient's clinical data assessment that include:

Medical diagnosis,Length of ICU stay, duration of connected with mechanical ventilation, mortalityrate (date of discharge from ICU).

Part III: Hemodynamic status assessment, which included respiratory system and cardiovascular system (heart rate, blood pressure, systolic and diastolic blood pressure and mean arterial blood pressure (one measurement per day).

Part IV: Assessment of the MV ventilator parameters(mode of ventilation, tidal volume (VT), fraction of inspired oxygen $\left(\mathrm{FiO}_{2}\right)$, positive end expiratory pressure (PEEP), Minute ventilation, pressure support (one time per day).

Tool II: Riker sedation-agitation scale.

This tool is developed by (Riker, 2001) used by the researcher to assess level of sedation. This scale is a Seven levels: three levels of agitation (levels 5 to 7), a 'calm and cooperative' level (level 4), and three levels of sedation (levels 1 to 3 ). All levels are defined by multiple ( 3 or 4 ) criteria andwas recently used by (Mirzaei1, et al., 2013). This tool was applied one time per day for seven days).

Too IIII: muscle assessment tool.

The researchers developed this tool after review of literatures (Donja, et al., 2013) to assess the muscle mass and strength .this tool compromised three parts.

Part 1:Muscle mass assessment of all upper and lower extremities by using measuring tape(Nomura, et al., 2018, Anunciação, et al., 2014) one measurement at the second day and seven day )to assess the legs andmid arms muscle circumference of the upper and lower, left and right sides .the mid arm circumference of the upper arm muscle measures the 
distance around the biceps and other muscles of the arm halfway between the shoulder and elbow joint.The leg circumference of the limb muscle measures the distance around the muscle of rectus femurs and muscle of vast us medial's.

Part11: Muscle function assessment by using muscle function assessment scale that developed by (Hahn, et al., 2015) to assess the ability and disability of the muscles movements. This scale graded from 0-10 scores. Score (0) denotes normal state, score (10)denote patient death.

Part 111: Muscle strength assessment by using Medical Research Council Scale (MRC). The MRC scale for muscle power was first published in 1943 in a document called 'Aids to the Investigation of Peripheral Nerve Injuries.(Herman's, et al., 2012, Karatzanose, et al., 2012, Hough, et al.,, 2011) to assess distribution of weakness and disease progression, treatment efficacy. The muscle scale grades muscle power on a scale of 0 to 5 in relation to the maximum expected for that muscle. In a recent comparison to an analogue scale the MRC scale is more reliable and accurate for clinical assessment in weak muscles (grades 0-3) while an analogue scales more reliable and accurate for the assessment of stronger muscles (grades 4 and 5).Three muscle groups in all four limbs were assessed with the MRC scale with values ranging from 0 (quadriplegia) to 60 (normal muscle strength). The following functions wereassessed: wrist flexion, forearm flexion, shoulder abduction, ankle dorsiflexion, knee extension, hip flexion. Patients with an MRC score $<48 / 60$ were diagnosed with ICUAW. The cut off limit of 48 for the MRC score was selected because it indicates clinically significant weakness and has been used previously for the clinical identification of ICUAW. (Sedaris, et al., 2013)

\section{Nursing Application}

The researchers through three phases collected the data:

A) Preparatory phase

B) Intervention phase

C) Evaluation phase

A) Preparatory phase

Patients were assigned into two groups (control group, interventional group) the researcher assessed and observed the patients who were receiving the routine hospital nursing care during the three phases of data collection.

- The study followed common ethical principles in clinical principles in clinical research and was approved by the local ethics.

- Informed consent was taken from the head of general and trauma units as well as relevant of the un conscious patients to carry out this study.
- The researcher based on the relevant literature reviewing developed the tool one, tool two,tool three.

- The developed tools were tested for content related validity by selected juries of five critical care medical and nursing professionals (Two critical care medical and three critical care nursing professionals) to assess adequacy of items of the tools.

- Every conscious patient was reassured that information obtained would be confidential and used only for the purpose of the study.

- The tools that developed by the researcher were tested for reliability by Cranach's Alpha and Reliability level was $82 \%$ for all the tools to assess the consistency and stability of the tools.

\section{Pilot study}

A pilot study carried out on number of six patients $(10 \%)$ to test the applicability of the tools appropriate study modification was done prior to data collection for the actual study; (the six patients were included with the sample).

\section{B) Intervention phase:}

\section{B-1.For the control group}

The patient received the routine hospital care (Range of motion exercises).

\section{B-2.For the intervention group}

They receive the same intervention as in the control group in addition to the application of neuromuscular electrical stimulation by usingelectrical musclestimulation devicefrom the second day of 1CU admission for seven days (Meesen, et al., 2010).

\section{$>$ Technique}

-Patients in the interventional group received a daily 30 minute session of neuromuscular electrical stimulation of the quadriceps femora's muscle as long as they were intubated and sedated.

-Electricalstimulation was applied to the right leg as well as the left leg, the right and the left arms of the same patient. .

-Patients were positioned in supine position and a half-roll pillow was positioned in the back of the knee to allow knee extension.

- Two active electrodes were placed on the muscle belly of them. Rectus-femora's and then vastusmedialis were aligned longitudinally to obtain an optimal force production and a reference electrode was placed in the inguinal area.

- All electrodes were fixed with elastic strapsto ensure that the position of the electrodes was the same throughout the intervention; the researcher marked reference points on the skin using semi-permanent ink.

-The intense of the stimulation (range, 0-120 am) was increased until contraction of the muscle of rectus femurs and the muscle of vastus medial's 
was visible and tension of the patellar ligament was clearly palpable.

-Each training session was preceded by a 5-minute warm-up trial of sub-maximal ES With the following characteristics: frequency, 20-50 Hz; pulses duration, 300-600msec; $10 \mathrm{sec}$ on, $20 \mathrm{sec}$ off. (RAF L, et al., 2010)

$>$ B-3.For both group

- Assess vital signs one time per day for seven days.

- Assess sedation scores once per day for seven days.

- Assess muscle function (ability and disability of muscle movements) once per day after NMES for seven days.

- Assess mechanical ventilation parameters once per day for seven days.

- Apply range of motion exercise from 2 to 4 times per day for seven days.

- Assess muscle strength once per day for seven days after NMES.

\section{Results}

Table (1): Frequency distribution of patient's number regarding socio-demographic characteristics and clinical data (total number of patients were 66).

\begin{tabular}{|c|c|c|c|c|}
\hline & Items & $\begin{array}{c}\text { Control group } \\
\mathbf{N}=\mathbf{3 3}\end{array}$ & $\begin{array}{l}\text { Intervention } \\
\text { group- } \mathrm{N}=33\end{array}$ & P value \\
\hline \multicolumn{2}{|l|}{ Age } & $32.86 \pm 8.65$ & $31.86 \pm 9.82$ & 0.664 \\
\hline \multirow[t]{2}{*}{ Sex } & Male & $26(78.8 \%)$ & $27(81.8 \%)$ & \multirow{2}{*}{0.235} \\
\hline & Female & $7(21.2 \%)$ & $6(18.2 \%)$ & \\
\hline \multirow[t]{9}{*}{ Diagnosis } & Guillain-Barre syndrome & $1(3 \%)$ & $1(3 \%)$ & \multirow{9}{*}{0.111} \\
\hline & mild brain edema /mild brain contusion & $12(36.4 \%)$ & $7(21.2 \%)$ & \\
\hline & multiple brain contusion /edema & $1(3 \%)$ & $3(9.1 \%)$ & \\
\hline & post arrest of poising/surgery & $6(18.2 \%)$ & $4(12.1 \%)$ & \\
\hline & shutter lung upper lobe & $0(0 \%)$ & $7(21.2 \%)$ & \\
\hline & intra cranial hemorrhage & $4(12.1 \%)$ & $6(18.1 \%)$ & \\
\hline & pulmonary embolism/pneumonia & $4(12.1 \%)$ & $1(3 \%)$ & \\
\hline & electrical/septic shock & $2(6.1 \%)$ & $1(3 \%)$ & \\
\hline & Subarachnoid hemorrhage & $3(9.1 \%)$ & $3(9.1 \%)$ & \\
\hline
\end{tabular}

NS there is no significant difference value > 0,05

(Independent T-test)
- Assessment of muscle mass at the second and seven day of admission.

C) Evaluation phase (outcomes evaluation phase)

- The researcher assessed the level of muscle strength and intensive care unit acquired weakness (ICUAW) by using MRC.

- The researcher assessedmuscle function by using muscle function assessment scale

- The researcher assessed the duration of mechanical ventilation and the length of stay in the intensive car unites.

- The researcher assessed the mortality rate by assessing number of dead cases.

\section{$>$ Statistical analysis:}

Statistical Package for the Social Sciences 20.0 (IBM SPSS Inc., Chicago, IL, USA) statistical software was used for statistical analysis. A $p$ value of $<0.05$ was considered as statistically significant. Categorical variables are presented as numbers and percentage (\%). $\chi 2$ test was used to evaluate the differences between the responder and the non-responder group. 


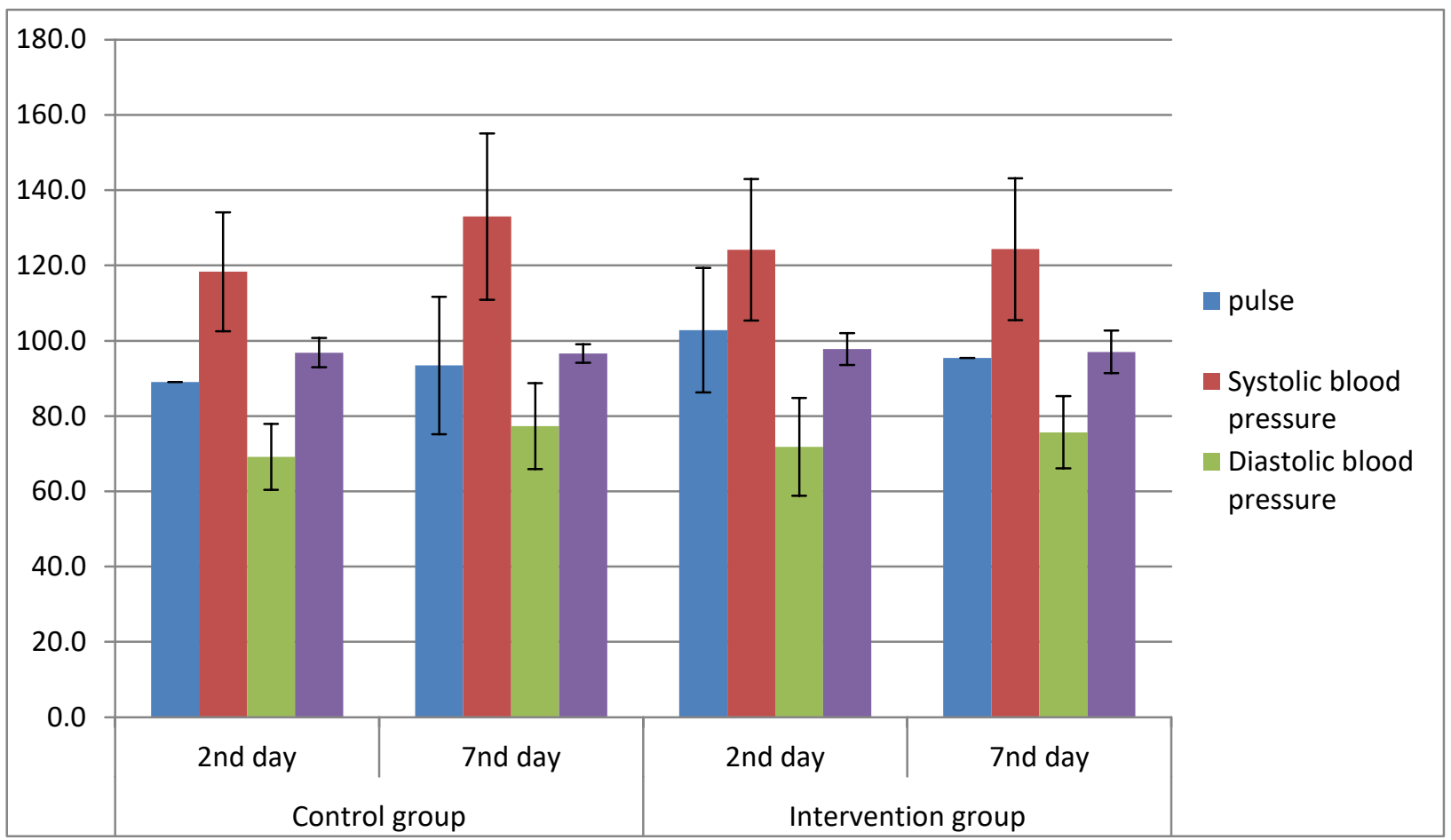

Figure (1): Comparison between the two groups related to vital signs at the second, seven day.

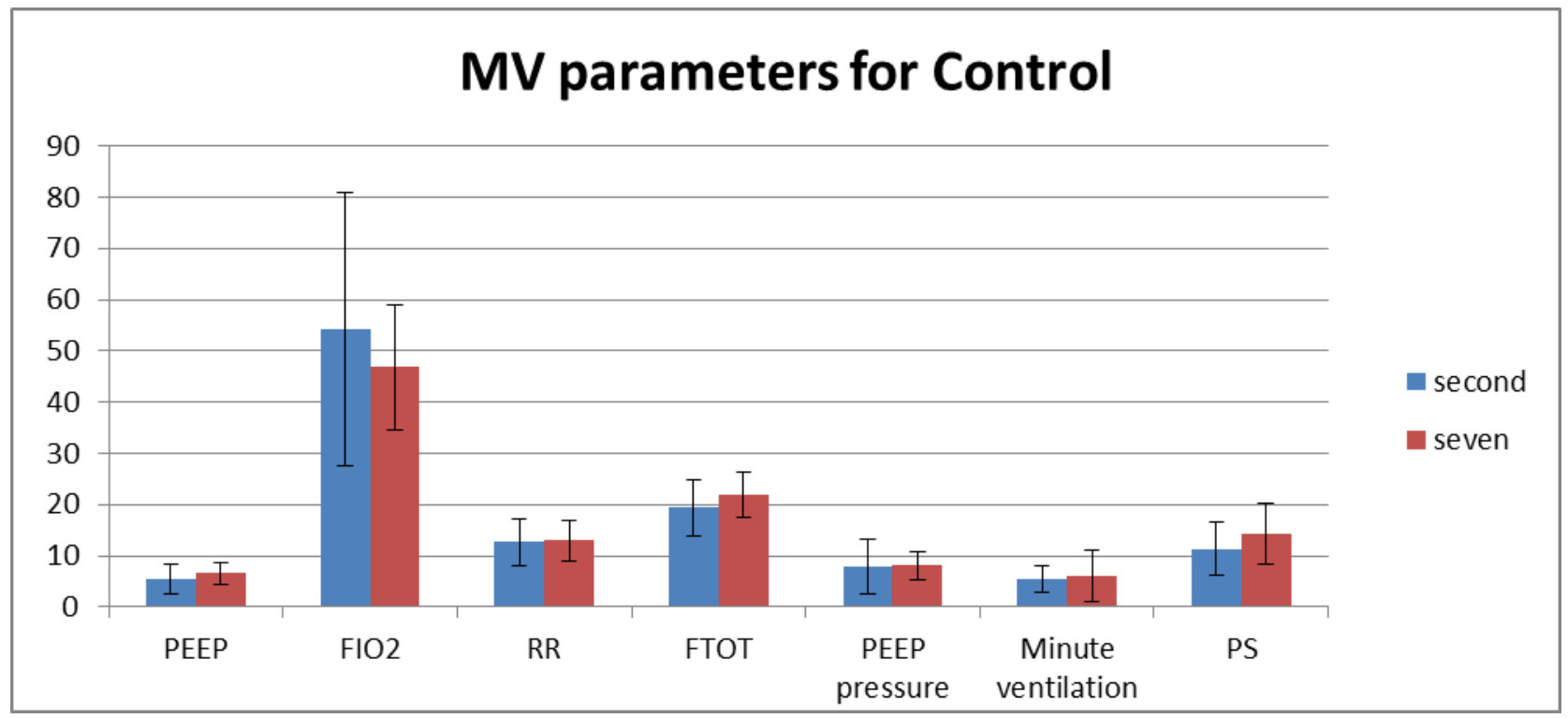

Figure (2):Comparison between the two groups in relation to mechanical ventilation parameters at the second, seven day of admission: 


\section{MV parameters for Intervention}

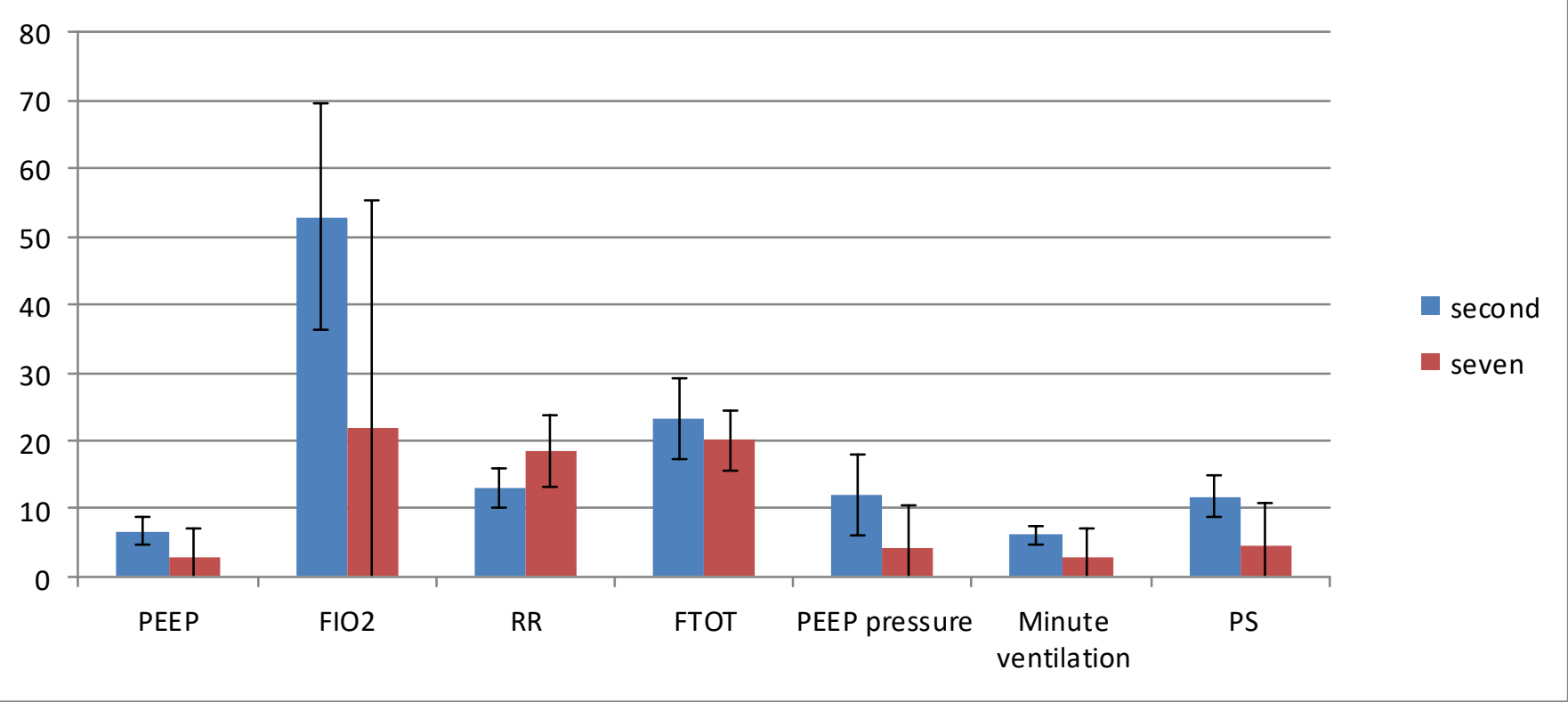

Figure \& Table (2): Frequency distribution of patients regarding sedation score at the Second, and seven day of admission:

\begin{tabular}{|l|c|c|c|c|c|c|}
\hline \multicolumn{1}{|c|}{ sedation score } & \multicolumn{2}{|c|}{ Control group } & \multicolumn{2}{c|}{ Interventional group } & \multicolumn{2}{c|}{ P value } \\
\hline Days & $2^{\text {nd }}$ day & $7^{\text {nd }}$ day & $2^{\text {nd }} d a y$ & $7^{\text {nd }}$ day & $2^{\text {nd }}$ day & $7^{\text {nd }}$ day \\
\hline Mean \pm SD & $2.13 \pm 0.73$ & $3.16 \pm 0.98$ & $2.19 \pm 0.52$ & $3.52 \pm 0.69$ & 0.69 & $0.087^{*}$ \\
\hline
\end{tabular}

NS there is no significant difference value > 0,05 * Significant difference at value $<0,05$

(Independent T-test)

Table (2): Comparison between the two groups in relation to upper limb circumferences at the second, seven day of admission.

\begin{tabular}{|l|l|l|l|l|}
\hline \multirow{2}{*}{$\begin{array}{c}\text { Upper limb } \\
\text { circumference }\end{array}$} & \multirow{2}{*}{ Days } & \multicolumn{1}{c|}{ Control group } & intervention group & \multirow{2}{*}{ P value } \\
\cline { 3 - 5 } & & \multicolumn{1}{|c|}{ Mean \pm SD } & Mean \pm SD & \\
\hline \multirow{2}{*}{ right arm } & Second day & $30.27 \pm 8.52$ & $34.99 \pm 9.37$ & $0.038^{*}$ \\
\cline { 2 - 6 } & Seven day & $29.26 \pm 8.61$ & $35.26 \pm 9.37$ & $0.009^{*}$ \\
\hline \multirow{2}{*}{ left arm } & Second day & $30.6 \pm 8.5$ & $35.01 \pm 9.34$ & $0.051^{*}$ \\
\cline { 2 - 5 } & seven day & $29.26 \pm 8.61$ & $35.79 \pm 10.03$ & $0.007^{*}$ \\
\hline
\end{tabular}

NS there is no significant difference value > 0, 05 * Significant difference at value $<0,05$

(Independent T-test)

Table (3): Comparison between the two groups in relation to lower limb calf circumferences at the second, seven day of admission:

\begin{tabular}{|l|c|c|c|c|}
\hline \multirow{2}{*}{$\begin{array}{c}\text { Lower limb } \\
\text { circumference }\end{array}$} & \multirow{2}{*}{ Days } & Control group & Intervention group & P value \\
\cline { 3 - 5 } & & Mean \pm SD & Mean \pm SD & \\
\hline \multirow{2}{*}{ right calf } & Second day & $36.9 \pm 10.0$ & $41.6 \pm 10.2$ & 0.062 \\
\cline { 2 - 5 } & Seven day & $39.6 \pm 10.3$ & $40.9 \pm 9.7$ & 0.615 \\
\hline \multirow{2}{*}{ left calf } & Second day & $36.9 \pm 10.0$ & $41.6 \pm 10.2$ & 0.062 \\
\cline { 2 - 5 } & seven day & $39.3 \pm 10.5$ & $41.6 \pm 10.2$ & 0.364 \\
\hline
\end{tabular}

NS there is no significant difference value > 0,05 * Significant difference at value $<0,05$

(Independent T-test)

Vol , (7) No, (16) March, 2019 
Table (4): Comparison between the two groups in relation to MRC (medical research council score) of upper limbs at the second, seven day of admission

\begin{tabular}{|l|l|l|l|l|l|l|}
\hline \multirow{2}{*}{ MRC 0f upper limb } & \multicolumn{2}{|c|}{ Control group } & \multicolumn{2}{c|}{ Intervention group } & \multicolumn{2}{c|}{ P value } \\
\cline { 2 - 7 } & $\mathbf{2}^{\text {nd }}$ day & $\mathbf{7}^{\text {nd }}$ day & $\mathbf{2}^{\text {nd }}$ day & $\mathbf{7}^{\text {nd }}$ day & $\mathbf{2}^{\text {nd }}$ day & $\mathbf{7}^{\text {nd }}$ day \\
\hline $\begin{array}{l}\text { Total MRC score of left } \\
\text { upper limb }\end{array}$ & $2.4 \pm 2.77$ & $5.1 \pm 3.71$ & $1.83 \pm 2.41$ & $12.22 \pm 4.33$ & 0.374 & $0.000 *$ \\
\hline $\begin{array}{l}\text { Total MRC score of right } \\
\text { upper limb }\end{array}$ & $1.4 \pm 2.92$ & $5.1 \pm 3.71$ & $1.83 \pm 2.41$ & $12.59 \pm 3.98$ & 0.511 & $0.000 *$ \\
\hline $\begin{array}{l}\text { Total upper right and left } \\
\text { limb MRC score }\end{array}$ & $3.8 \pm 5.57$ & $10.2 \pm 7.41$ & $3.67 \pm 4.82$ & $24.80 \pm 8.03$ & 0.917 & $0.000 *$ \\
\hline
\end{tabular}

NS there is no significant difference value $>0,05 \quad *$ Significant difference at value $<0,05$

(Independent T-test)

Table (5): Comparison between the two groups in relation to total MRC score (medical research council score) of lower limbs at the second, seven day of admission.

\begin{tabular}{|l|c|c|c|c|c|c|}
\hline \multirow{2}{*}{$\begin{array}{c}\text { MRC of } \\
\text { lower limb }\end{array}$} & \multicolumn{2}{|c|}{ Control group } & \multicolumn{2}{c|}{ Interventional group } & \multicolumn{2}{c|}{ P value } \\
\cline { 2 - 7 } & $\mathbf{2}^{\text {nd }}$ day & $\mathbf{7}^{\text {nd }}$ day & $\mathbf{2}^{\text {nd }}$ day & $\mathbf{7}^{\text {nd }}$ day & $\mathbf{2}^{\text {nd }}$ day & $\mathbf{7}^{\text {nd }}$ day \\
\hline $\begin{array}{l}\text { Total MRC } \\
\text { score of left } \\
\text { lower limb }\end{array}$ & $1.4 \pm 2.92$ & $5.1 \pm 3.71$ & $1.83 \pm 2.41$ & $12.25 \pm 4.261$ & 0.511 & $0.000^{*}$ \\
\hline $\begin{array}{l}\text { Total MRC } \\
\text { score of right } \\
\text { lower limb }\end{array}$ & $1.4 \pm 2.92$ & $6.3 \pm 6.66$ & $1.83 \pm 2.41$ & $12.59 \pm 3.98$ & 0.511 & $0.000 *$ \\
\hline $\begin{array}{l}\text { Total lower } \\
\text { right and left } \\
\text { limb MRC } \\
\text { score }\end{array}$ & $2.8 \pm 5.84$ & $11.4 \pm 9.76$ & $3.67 \pm 4.81$ & $24.83 \pm 8.0$ & 0.511 & $0.000 *$ \\
\hline
\end{tabular}

NS there is no significant difference value >0,05 * *ignificant difference at value $<0,05$

(Independent T-test)

Table (6): Comparison between the two groups in relation to total MRC scores (medical research council score) of upper and lower limbs in thedifferent days).

\begin{tabular}{|l|c|c|c|c|c|c|}
\hline $\begin{array}{c}\text { Total MRC score } \\
\text { of upper and } \\
\text { lower limb }\end{array}$ & \multicolumn{2}{|c|}{ Control group } & \multicolumn{2}{|c|}{ Intervention group } & \multicolumn{2}{c|}{ P value } \\
\hline Days & $2^{\text {nd }}$ day & $7^{\text {nd }}$ day & $2^{\text {nd }}$ day & $7^{\text {nd }}$ day & $2^{\text {nd }}$ day & $7^{\text {nd }}$ day \\
\hline Mean \pm SD & $14.90 \pm 7.65$ & $23.70 \pm 11.58$ & $14.33 \pm 4.82$ & $47.66 \pm 16.84$ & 0.71 & $0.000 *$ \\
\hline
\end{tabular}

NS there is no significant difference value >0,05 * *ignificant difference at value $<0,05$

(Independent T-test)

Table (7):Comparison between the two groups in relation to functional assessment score at the second, seven day of admission.

\begin{tabular}{|l|l|l|l|l|l|l|}
\hline $\begin{array}{c}\text { functional assessment } \\
\text { scale }\end{array}$ & \multicolumn{2}{|c|}{ Control group } & \multicolumn{2}{c|}{ Intervention group } & \multicolumn{2}{c|}{ P value } \\
\hline Days & $2^{\text {nd }}$ day & $7^{\text {nd }}$ day & $2^{\text {nd }}$ day & $7^{\text {nd }}$ day & $2^{\text {nd }}$ day & $7^{\text {nd }}$ day \\
\hline Mean \pm SD & $7.77 \pm 0.43$ & $7.13 \pm 0.68$ & $7.83 \pm 0.61$ & $5 \pm 2.08$ & 0.616 & $0.000 *$ \\
\hline
\end{tabular}

NS there is no significant difference value > 0,05 * Significant difference at value $<0,05$

(Independent T-test) 
Table (8): Frequency distribution of the ICAW (intensive car unite acquired weakness) in the two groups.

\begin{tabular}{|c|c|c|c|c|}
\hline items & ICAW(MRC <48) & control group & intervention group & $P$ value \\
\hline \multirow{4}{*}{$\begin{array}{l}\text { second } \\
\text { day }\end{array}$} & yes & 0 & 0 & \multirow{4}{*}{1} \\
\hline & $\%$ & $0 \%$ & $0 \%$ & \\
\hline & no & 33 & 33 & \\
\hline & $\%$ & $100 \%$ & $100 \%$ & \\
\hline \multirow{4}{*}{ seven day } & yes & 26 & 8 & \multirow{4}{*}{$<0.001 *$} \\
\hline & $\%$ & $78.8 \%$ & $24.2 \%$ & \\
\hline & no & 7 & 25 & \\
\hline & $\%$ & $21.2 \%$ & $75.8 \%$ & \\
\hline
\end{tabular}

NS there is no significant difference value > 0, 05

(Independent T-test)

Table (9): Comparison between two groups regarding patients out comes (mechanical ventilation duration, mortality, length of ICU stay).

\begin{tabular}{|l|c|c|c|}
\hline \multicolumn{1}{|c|}{ out comes } & Control group & Intervention group & P value \\
\hline \multirow{2}{*}{ MV duration } & mean \pm SD & mean \pm SD & \\
\cline { 2 - 4 } & $18.03 \pm 14.56$ & $3.19 \pm 1.51$ & $0.000^{*}$ \\
\hline Mortality & 17 & 5 & $0.000^{*}$ \\
\hline ICU stay & $20.53 \pm 16.26$ & $6.39 \pm 1.86$ & $0.000^{*}$ \\
\hline
\end{tabular}

NS there is no significant difference value > 0, 05

(Independent T-test)

* Significant difference at value $<0,05$

Table (1): Shows the frequency distribution of the Intervention and the control groups regarding sociodemographic characteristics and clinical data:

Regarding to age the results of the current study revealed that the mean age of control and intervention group were $(32.86 \pm 8.65)$ versus $(31.86 \pm 9.82)$ respectively. Regarding to sex, it was noticed that a highly percent of patients in control and intervention group were male 26 (78.8\%) versus27(81.8\%) respectively, and low percent of patients of controland intervention group were female $7(21.2 \%)$ versus6(18.2\%) and there was no statistically significant difference between the two groups (p. value > 0, 05).

Figure (1): Shows comparison between the two groups related to vital signs.

There was no statistically significant difference between the two groups regarding almost of items of the vital signs through the second, seven day.

Figure (2): Shows comparison between the two groups related to MV parameters: there was a statistically significant difference between the two groups regarding almost of mechanical ventilation parameters at the second, seven day of admission ( $\mathrm{p}$. value< 0,05 ).

Figure \& Table (3): Shows comparison between the two groups related to sedation score: there was no statistically significant difference in sedation score of the control and intervention group in second and seven day (p. value> 0, 05).
Table (2): Shows comparison between the two groups related to upper left and right arm circumference: The mid arm circumference of control and intervention group were $(29.26 \pm 8.61)$ versus (35.26 \pm 9.37$),(29.26 \pm 8.61)$ versus $(35.79 \pm 10.3)$ respectively in the seven day ( $\mathrm{p}$ value $<0.05$ ).

Table (3): Shows comparison between the two groups related to lower calf circumference:

The calf circumference of control group and the intervention group were $(39.6 \pm 10.3)$ versus (40.9 \pm 9.7$),(39.3 \pm 10.6)$ versus $(41.6 \pm 10.2)$ in the seven-day respectively ( $\mathrm{p}$ value $>0.05$ ).

Table (4): Shows comparison between the two groups related to MRC score of upper limbs: there was a significant increase of MRC score of intervention group versus the control group $(24.80 \pm 8.03)$ versus $(10.2 \pm 7.41)$ respectively in the seven day (p. value $<0,05)$.

Table (5): Shows comparison between the two groups related to MRC score of lower limbs: there was a significant increase of MRC score of intervention group versus the control group $(24.83 \pm 8.0)$ versus $(11.4 \pm 9.76)$ respectively in the seven day (p. value $<0,05$ ).

Table (6): Shows comparison between the two groups related to MRC score of upper and lower limbs: there was a significant increase of MRC score of intervention groupthan the control group $(47.66 \pm 16.84)$ versus $(23.70 \pm 11.58)$ respectively in the seven day ( $\mathrm{p}$ value $<0.05$ ). 
Table (7): Shows comparison between the two groups related to functional assessment scale: there was a significant improvement in patient's functional assessment scores of intervention group than the control group $(5 \pm 2.08)$ versus $(7.13 \pm 0.68)$ at the seven day ( $\mathrm{p}$ value $<0.05$ ).

Table (8): Shows comparison between the two groups related to ICAW: there was a significant decrease in percentage of patients with ICAW in the intervention group than the control group (21.2\%) versus $(75.8 \%)$ at the seven day ( $\mathrm{p}$ value $<0.05)$.

Table (9): Shows comparison between the two groups related to patients out comes: There was a significant increase in mechanical ventilation duration, length of stay and Mortality rate in control group than the intervention group $(18.03 \pm 14.56)$ versus $(3.19 \pm 1.51),(20.53 \pm 16.26)$ versus $(6.39 \pm 1.86)$ respectively. There was a statistically significant difference between the two groups regarding patients out comes ( $\mathrm{p}$ value $<0.05$ ).

\section{Discussion}

Critically ill and mechanically ventilated patients are often given strict bed rest and they are sometimes completely immobilized because of the severity of their illness and administration of drugs such as sedatives and neuromuscular blocking agents (Şenduran, 2012)

Demographic characteristics of studied subject

As regard to sex, the studied subjects showed that more than three fourth of studied patients were young males and less than half of studied were female. This finding could be attributed to that young males are more exposure to accidents due to the nature of physical activity and culture of community. These findings were supported by (Karatzanos, et al., 2012) who reported that more than three fourth of studied subject were male.

Regarding to patients diagnosis of the study sample, the finding of the current study revealed that the most common diagnosis were mild brain edema /mild brain contusion but less common diagnosis were Guillain-Barre syndrome and electrical/septic shock. These findings were supported by (Abu-Khaber, et al., 2013, Routsi, et al., 2010) study, which also showed no statistically significant difference between the EMS groups compared to control group.

Concerning to Socio-demographic characteristics there was no significant difference between the two groups .It can be attributed by that all patients in the two groups were homogeneous.

Concerning to patients (heart rate), the finding of the current study revealed that there was no statistically significant difference between the two groups in the seven day. This finding could be attributed by that applying neuromuscular electrical stimulation session does not cause load burden on the heart. The Current results are in contrast with (youngish, et al., 2015., Freitas, et al., 2012) study which showed significant increase in mean scores of heart and respiratory rate were observed after 5 and 20 min minutes of intervention compared to the mean scores before intervention

Regarding to systolic, diastolic blood pressure of the study sample, the finding of the current study revealed that there was no statistically significant difference between the two groups. The Current results were matching with (Freitas, et al., 2012) who mention that there was no statistically significant difference between the two groups.

Concerning to oxygen saturation of the study sample, the finding of the current study revealed that there was clinical increase in oxygen saturation in the interventional group without statistically difference between the interventional groups and the control group .This finding could be attributed by that applying neuromuscular electrical stimulation session improve respiratory out comes .These Current results were in contrast with (youngish, et al., 2015)study, which show a significant decrease in oxygen saturation means scores were observed after 5 and 20 min minutes of intervention compared to the mean scores before intervention. While after $60 \mathrm{~min}$ the mean scores were nearly equal to before intervention. Concerning to mechanical ventilation parameters there was significantly different between the two groups, mechanical ventilation parameters were better in the interventional group versus the control group. The present study is in contrast with (Gerald, et al., 2017) that showed that there was no relationship between changes in parameters and the total time spends performing physiotherapy.

Related to the muscle mass circumference of the upper limbs there was asignificantly increase in the muscle thickness of interventional group versus the control group. This finding could be attributed by applying neuromuscular electrical stimulation sessions prevent muscle atrophy and improve muscle function. Current results were contrast with (Rodriguez, etal 2012); study found no significant changes in muscle thickness between the stimulated and contralateral biceps muscle.

Related to the muscle mass circumference of the lower calf circumference, the finding of the current study revealed that there was no statistically significant difference of the muscle thickness between the two groups. This finding could be attributed by effecting of gravity causing edema of the lower limbs in the control group. Current results were matching with (Poulsen, et al., 2011) study, which show no differences in muscle volume loss between the stimulated and contralateral quadriceps. 
Related to muscle strength of the upper and the lower limbs as evaluated with the MRC Scale there was statistically significantly higher in patients assigned to the interventional group as compared with the control group. This higher score in the interventional group could be attributed by that applying neuromuscular electrical stimulation sessions achieved higher level of muscle strength in the interventional group in the seven day. Current results were matching with (Routsi, et al., 2010, Wagecka, etal 2014, Karatzanos, et al., 2012, Rodriguez, et al., 2012) study which showed better MRCS in the EMS group compared to control.

Related to functional assessment score there was significantly higher scores in the control group that indicate worseness in muscles function of patients in compared with the interventional group. This higher scores in the control group could be attributed by that, higher level of muscle weakness occurred in the control group. Current results were matching with (Leite, et al., 2018) study that showed, a statistically significant difference was found with higher scores in the control group compared to EMS group.

Regarding ICUAW. All patients in the two groups had ICUAW, There was a statistically significantly decrease in the number of patients who had ICUAW in interventional group versus control group in the seven day. That decreased number of patients who had ICUAW in the interventional group could be attributed by that higher level of muscle strength achieved by applying neuromuscular electrical stimulation sessions. Current results are matchingwith(Abu-Khaber,etal 2013)that show the striking finding that MRCS values starting from day 2 post mechanical ventilation in both groups were below 48 - which is considered as the cut-off value for diagnosis of ICUAMW.

Concerning to the duration of $\mathrm{MV}$, the finding of the current study revealed that there was significantly shorter duration in the NMES group when compared with control group. Current results are matching with (Leite, et al., 2018). That showed daily consecutive electrical stimulation sessions produced better results in terms of MV duration, and functional status than those in the control group.

Concerning to the weaning of patients from mechanical ventilation in the current study, the EMS sessions had a really significant role in facilitating the weaning process or not as the number of days on mechanical ventilation showed a better outcome on the EMS group versus the control group $(p=0.000)$ the current results are matching with (Routsi, et al., 2010) Where the duration of mechanical ventilation was shorter for patients assigned to the EMS group compared with patients in the control group.
Related to ICU length of stay (days) of the study sample, the finding of the current study revealed that there was significantly shorter in the duration of ICU staying the interventional group when compared with control group. The current results are matching with (Routsi, et al., 2010) study found although the duration of ICU stay shorter in patients assigned to the EMS group compared with those in the control group.

Related to mortality rate: there were no further studies done on the use of EMS in critically ill patients investigated the mortality as an endpoint for assessment of the benefit of this technique but it seems quiet logical that minimizing the days of mechanical ventilation and facilitation of rapid weaning will decrease the overall complications and might have a beneficial effect through reducing mortality. No significant complications were encountered during the usage of EMS. All Patients in the EMS group completed their sessions until the end of the study.

\section{Conclusion}

The present study highlighted the therapeutic effect of nursing application of neuromuscular Electrical stimulation on muscle function in critically ill patients out comes. Based on the results of this study, it could be concluded thatelectrical muscle stimulation of intervention group had best outcomes for peripheral muscle strength compared with controls among mechanically ventilated critically ill subjects and promoted functional independence and decreased length of hospitalization.application of EMS sessions could not prevent the occurrence of ICUAMW but it can minimize the degree of weakness as shown from MRCS.

\section{Recommendations}

Based on the finding of the currentstudy, the following recommendations are suggested:

- Emphasize the importance of using neuromuscular Electrical stimulation session.

- Identify high risk patients to prevent complication.

- Regular checking of electrode placing to avoid occurrence of discomfort and pain.

- Appropriate follow up of patients' (status, muscles mass circumference, muscle function and outcomes) that have undergone neuromuscular Electrical stimulation session for assessment and detection of occurrence of muscle function progress.

- Keep the electrical muscle stimulation device available in the intensive care units.

- Further studies are needed on large sample size and in multi medical hospital canters for generalization,examining the natural history of ICUAW in ICU survivors and the chronic critically 
illto fully elucidate the mechanisms by which immobility and other aspects of critical illness lead to ICUAW forunderstanding the associations between the ICUAW, physical function, and quality of life in these patients.

\section{References}

1. Ali N., O'Brien Jar J., Hoffmann S., (2008): Acquired weakness, handgrip strength, and mortality in critically ill patients. Am Respire Crit Care Med; 178:2618.

2. Anunciação, P., Ribeiro, R., Pereira, M., Comunian, M., (2014): Different measurements of waist circumference and sagittal abdominal diameter and their relationship with cardio metabolic risk factors in elderly men. J. Hum. Nutr. Diet. 27, 1627.

3. Wagecka, G., Nunesa, F., Silvab, Damascenob, M., de Noronhaa (2014): Application and effects of neuromuscular electrical stimulation in critically ill patients: Systematic revie. Med Intensive. 38(7):444454.

4. Routsi, V., Gerovasili, \& Vasileiadis (2010): "Electrical muscle stimulation prevents critical illnesspolyneuromyopathy: randomized parallel intervention trial "Critical Care, vol.14, no. 2, pp. 118-128.

5. Hough C., Ellen Caldwell B., (2011): Manual muscle strength testing of critically ill patients: feasibility and interobserver agreement. Critical Care, 15:R43 http:// forum. com/ content/ 15/1/R43.

6. Donja M., Mijnarends Email, Judith. Meijers, Ruud J., Halfens, Sovianneter Borg, Yvette C. Luiking, , Sjors Verlaan, , Daniela Schoberer, Alfonso J., Cruz Jentoft, Luc J., (2013): Validity and Reliability of Tools to Measure Muscle Mass, Strength, and Physical Performance in Community-Dwelling Older People. Volume 14, Issue 3, Pages 170-178.

7. Eliane Regina Ferreira Sernache de FreitasI; RenataSerrou da SilvaBersiII; Mariana Yuri KuromotoII; Silviane de Camargo SlembarskII;Ana Paula AyumiSatoII; Marcela Quadros Carvalho III. (2012): Effects of passive mobilization on acute hemodynamic responses in mechanically ventilated patients. Rev. Bras. Ter. Intensive vol.24 no.1.

8. Youngish G., \& Ahmed S., (2015): Effectiveness of Passive Range of Motion Exercises on Hemodynamic parameters and Behavioral pain Intensity among Adult Mechanically Ventilated Patients. Journal of
Nursing and Health Science (IOSR-JNHS) eISSN: 2320-1959.p- ISSN: 2320-1940 Volume 4, Issue 6 Ver. I (Nov. - Dec.), PP 47-59 .www.iosr journals.org.

9. Georgios Sidiras, Vasiliki Gerovasili Irene Patsaki, Eleftherios Karatzanos, Emmanouil Papadopoulos Vasiliki Markaki Georgios Strantzalis \& Serafim Nanas. (2013): Treatment of muscle weakness and related complications science journal; Apr-Jun2013, Vol. 7 Issue 2, p188.

10. Gerald S., Spinks, Paul F., Netzel, Emily N., Valentine, Leigh Ann P., Callahan. (2017): Effect of Physical Therapy on Respiratory Parameters in Mechanically Ventilated Patients. American Journal of Respiratory and Critical Care Medicine 2017; 195:A2740.

11. AbuKhaber, Abouelela, \& E., Abdelkarim. (2013): "Effect of electrical muscle stimulation on prevention of ICU acquired muscle weakness and facilitatingweaning from mechanicalventilation," Alexandria Journal of Medicine, vol. 49, no. 4, pp. 309-315, 2013.

12.Hahn A., Bolton C., \& Pillay N., (2015): Plasma exchange therapy in chronic inflammatory demyelinating polyneuropathy. A double blind, sham controlled, and crosses over study .Brain 1996; 119: 105566. [Medline] Last Updated on Thursday, 12/8/2015 9:49:45 AM.

13. Hermans G., Clerckx B., Vanhullebusch T., (2012): Interobserver agreement of Medical Research Council sum-score and handgrip strength in the intensive care unit. Muscle Nerve 2012; 45: 18-25.

14. Zanni, R., Korupolu, E., Fran (2010): "Rehabilitation therapy and outcomes in acute respiratory failure: an observational pilot project," Journal of Critical Care, vol. 25, no. 2, pp. 254-262.

15. Karatzanos E., Gerovasili V., \& Zervakis D., (2012):Electrical muscle stimulation: an effective form of exercise and early mobilization to preserve muscle strength in critically ill patients. Crit Care Res Pract: 432752 .doi:. 1155/ 2012/ 432752.

16. KyeongyoonWoo Woo, Jeongmin Kim Kim, Hype Bin Kim, \& Hyun woo Choi1, Kibum Kim, Donghyung Lee, \& Sung won Na1. (2018): The Effect of Electrical Muscle Stimulation and In-bed cycling on Muscle Strength and Mass of Mechanically Ventilated Patients: A Pilot Study. Acute and Critical Care 33(1):16-22. 
17. Kho, A., Truong, J., Zanni (2015): "Neuromuscular electrical stimulation in mechanically ventilated patients: a randomized, sham-controlled pilot trial with blinded outcome assessment," Journal of Critical Care, vol. 30, no. 1, pp. 32-39.

18. Marcela Aparecida Leite, Erica Fernando Osaka, Jacqueline Albert, Claudia Rajang Limeade Mace doCosta, Alessandra Magdalena Garcia, Fran celadon Naas cement Czar pies ski,Sully Mariko glassware, Glad son Ricardo Flore Berta lain, Maury Cesar Jorge, \& Pericles Almeida Delano Duarte. (2018): effects of neuromuscular electrical stimulation of the Quadriceps and diaphragm in Critically Ill Patients: A Pilot Study.CriticalCareResearchandPracticeVolum e2018, Article D4298583,8pageshttps://doi.org/10.1155//4 29858.

19. Mirzaei M., Pourmirza Kalhori R., Moradi G., Khatoni A., Rezaei M., (2013): The effect of Riker sedation-agitation scale on clinical outcome of patients under coronary artery bypass graft surgery. Iran J Crit Care Nurs2013, 6(4):223-228

20. Poulsen J., Moller K., Jensen C., Weisdorf S., Kehlet H., Perner A., (2011): Effect of transcutaneous electrical muscle stimulation on muscle volume in patients with septic shock .Crit Care Med.; 39:456461.doi:10.1097/CCM.0b013e318205c 7bc. [PubMed][CrossRef]

21. Raf L., Meesen, Paul Dendale, Koen Cuypers, Jan Berger, Ann Hermans, Herbert Thijs, Oron Levin (2010): Neuromuscular electrical stimulation as a possible mean to prevent muscle tissue wasting in artificially ventilated and sedated patients in the intensive care unit Neuromodulator 2010; 13: 315-321.

22. Riker R., Fraser G., Simmons L., Wilkins M., (2001): Validating the sedation-agitation scale with the spectral index and visual analog scale in adult icu patients after cardiac surgery. Intensive Care med.; 27(4):8538.

23. Rodriguez P., Setten M., Maskin L., Bonelli I., Vidomlansky S., AttieS, Frosiani S., \& Kozima S., Valentini R., (2012): Muscle weakness in septic patients requiring mechanical ventilation: protective effect of transcutaneous neuromuscular electrical stimulation. J Crit Care. 2012; 27:e311-318. [PubMed].

24. Şenduran M., Genç A., Akan M., Gunerli A., (2012): Effects of mobilization on hemodynamic and respiratory responses in critically ill patients. Fizyoter Rehabil.; 23(1):3-9.

25. Takuo Nomura, Toshihiro Kawae, Hiroaki Kataoka, \& Yukio Ikeda (2018): Assessment of lower extremity muscle mass, muscle strength, and exercise therapy in elderly patients with diabetes mellitus, Environ Health Premed.; 23: 20 Published online 2018 May 17. Doi: 10.1186/s12199-018-0710-7. 